\title{
ILLUMINANCE AND LUMINANCE BASED RATIOS IN THE SCOPE OF PERFORMANCE TESTING OF A LIGHT SHELF-REFLECTIVE LOUVER SYSTEM IN A LIBRARY READING ROOM
}

\author{
Merve Öner ${ }^{1}$ and Tuğçe Kazanasmaz ${ }^{2}$ \\ 1 The University of Pisa, Pisa, Italy \\ ${ }^{2}$ Izmir Institute of Technology, Izmir, Turkey \\ E-mail:m.oner@studenti.unipi.it
}

\begin{abstract}
Uncontrolled daylight brings visual and thermal problems that may result in negative interactions with user comfort, productivity, well-being, and human health. Library spaces, in which reading, writing, and computer task activities are performed, need to be well designed in terms of daylight performance to enhance user satisfaction. The focus of this study is to make a performance test of a light shelf-reflective louver system to improve the visual performance conditions of a library reading room. First, the instrumental monitoring of existing daylighting conditions was performed. Second, Relux model was prepared to evaluate luminance patterns and illuminance distribution. Third, a new light shelf-reflective louver system was proposed based on the insufficiencies of the simulation results. The performance of the new system was found highly satisfactory based on the findings of enhanced luminance patterns and uniformity ratios especially at the points near the windows.
\end{abstract}

Keywords: daylighting, visual performance, library, illuminance, luminance, light shelf, reflective louver

\section{INTRODUCTION}

Libraries are the spaces where people fulfil both their learning and working activities; so, visual performance ought to be considered initially. These kinds of spaces have to be responsible for users to execute their work efficiently with no deficiency in visual acuity or comfort considering the whole aspects of performance issues associated with lighting [1]. Required illuminance values are needed to be satisfied; luminance/contrast relationship is to be well controlled with luminance ratios, which are determined by illuminance and reflectance of surroundings in the visual field. Eyes can adapt to varying luminances rapidly in a properly designed visual environment; their tiredness can decrease as well.

A well-daylit library stimulates success, increases the duration of stay, enhances well-being, and regulates the seating distribution $[2,3]$. Benefits of daylight have become more significant in library planning within the context of visual comfort for various intended usages such as paperwork, computer-based work, bookshelf browsing, and reading books, journals, and digital sources $[4,5]$. The amount of daylight for different purposes is associated with the luminance of surfaces within the field of view [6]. To obtain good visibility, an adequate amount of light for the task and the glare control are ought to be precisely existing [7].

Daylight redirecting systems provide such solutions to block the excessive illuminance that causes glare and heat gain problems and supply daylight to deep spaces [8]. Kontadakis et al. tested moveable mirrors fixed on a light shelf that are able to track the sun in a south facing deep office. Illuminance increased during both $152 \%$ in summer and $12.5 \%$ winter solstices comparing to the actual case 
Table 1. Photometrical Features of the Surfaces

\begin{tabular}{|c|c|}
\hline Surface & Reflectance/Transmittance [\%] \\
\hline Walls & 73 \\
\hline Floor & 37 \\
\hline Ceiling & 78 \\
\hline Desks & 47 \\
\hline Glazing & 80 \\
\hline
\end{tabular}

[9]. Dogan and Stec developed a horizontal light shelf with a row of mirror tiles that can be tilted in two-axis according to sun movement. They observed almost $20 \%$ daylight performance improvement and decrease in glare [5].

This study focuses on the evaluation of visual performance conditions in terms of illuminance and luminance distributions in an academic library, due to the above considerations and lack of studies to improve the visual quality of users in library spaces. The aim is to examine the effectiveness of a light shelf and reflective blinds in such problematic zones that are exposed to unsatisfied or excessive luminance and illuminance distributions on both VDU and paper tasks.

\section{METHODOLOGY}

\subsection{Library Reading Room}

The experiments were conducted in the library of Izmir Institute of Technology $\left(38.19^{\circ} \mathrm{N}\right.$, $26.37^{\circ} \mathrm{E}$ ). It has an orientation along the $60^{\circ}$ east of south axis. The reading room (L $29.70 \mathrm{~m} \times \mathrm{W}$ $19.00 \mathrm{~m} \times \mathrm{H} 4.30 \mathrm{~m}$ ) has north-east, south-west, and north-west oriented facades, which are fully glazed. The workplane layout is divided into three zones: two seating zones and the center zone with bookshelves (Fig. 1).

Material characterization was performed onsite using luminance/illuminance based technique to practically and basically get information about materials on-site due to the literature [10]. An illuminance meter and a luminance meter were used (Table 1). The equation of Lambertian reflectance was the basis for the reflectance calculation. The windows consist of double layer glazing, whose transmittance was measured and calculated due to the literature [11].

\subsection{Validation Process}

Horizontal illuminance was chosen as the indicator, where the paper task was performed. Measurements were carried out with an illuminance meter on June 20 and July 20. In total, 131 measurement points were set with a height of $0.76 \mathrm{~m}$ above the ground. The readings were afterwards compared with illuminance outputs from Relux-based simulation model, which was generated with identical building characteristics. The coefficient of determination $\left(R^{2}\right)$ values ranged between $51 \%$ and $78 \%$ for all simulations on the above dates indicating the acceptable accuracy of the simulation model. Keeping in mind the large floor area of the experimental

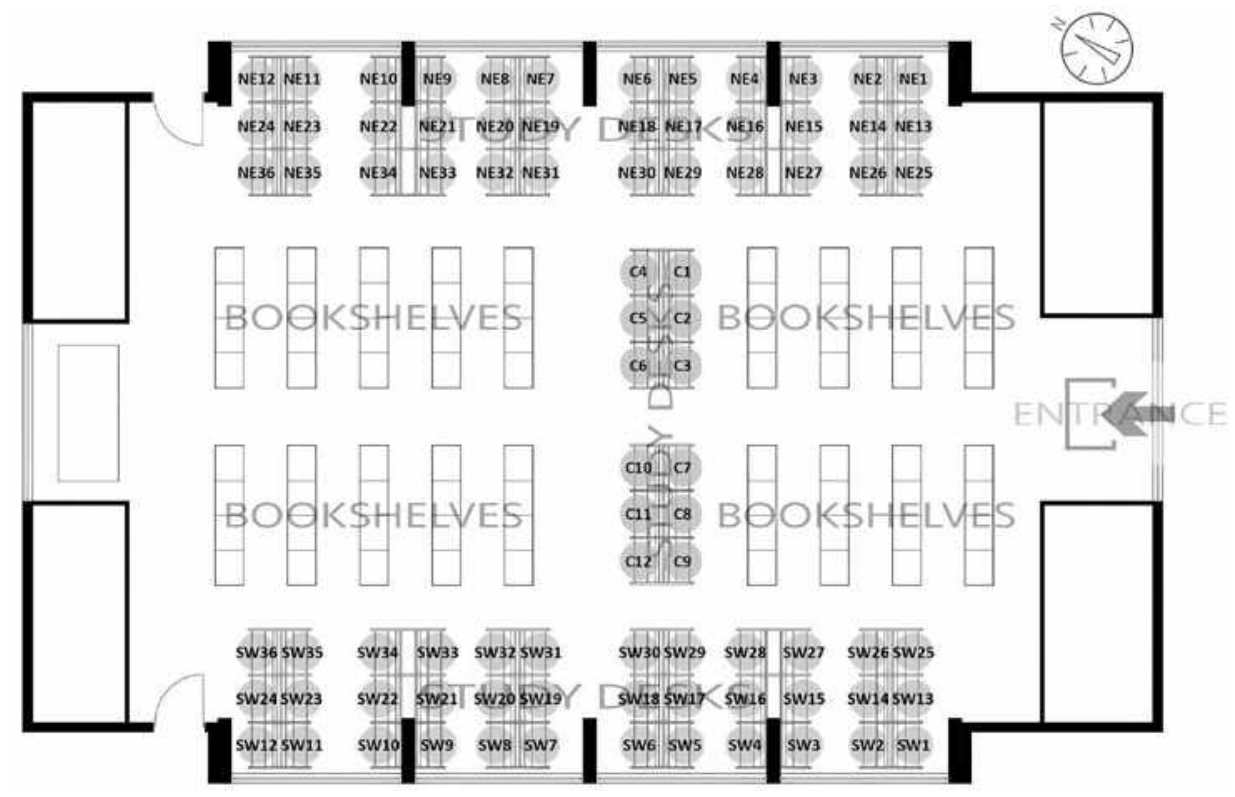

Fig. 1. Measurement locations: NE1-NE36 (nort-east points), SW1-SW36 (southwest points), and $\mathrm{C} 1$ C12 (centre zone) 
Table 2. Statistical Kesults of Errors

\begin{tabular}{|c|c|c|c|}
\hline & $\boldsymbol{R}^{\mathbf{2}}$ & MPE & CV(RMSD) \\
\hline June 20, 2.00 pm & 0.51 & $10 \%$ & $21.1 \%$ \\
\hline July 20, $11.00 \mathrm{am}$ & 0.67 & $20 \%$ & $21.7 \%$ \\
\hline July 20, $12.30 \mathrm{pm}$ & 0.78 & $20 \%$ & $19.8 \%$ \\
\hline July 20,3.30 pm & 0.71 & $55 \%$ & $31.1 \%$ \\
\hline
\end{tabular}

space and furniture, the error margin may be considered acceptable. Further, mean percentage error (MPE) values and coefficient of variation (relative mean square deviation) (CV(RMSD)) are calculated to indicate the averaged error and deviation of measured to simulated illuminance values (Table 2).

\subsection{Identification of the Problem}

The library reading room was analyzed in Relux under CIE intermediate sky with sun, on the solstice and equinox dates at 12:30 pm within the scope of illuminance and luminance based ratio standards of library spaces. A total of 84 points were studied at a height of $0.76 \mathrm{~m}$ on the centre of each study desk, which was arranged with a computer screen and a white paper placed in front of the occupant (Fig. 1). The objective in this section is to identify the problem in daylight distribution measuring horizontal illuminance on the workplane and luminance pattern analysis in the visual field.

\subsubsection{Luminance Pattern Analysis and Determination of the Most Problematic View Points}

Luminance distribution of each viewpoint was analysed on the solstice and equinox days at 12:30 $\mathrm{pm}$. Three points were determined as receiving the least uniform luminance distribution due to recommended luminance ratios. To achieve this, luminance on screen, white paper, desk, partition, wall, general surrounding, and sidewall adjacent to the window were evaluated according to the luminance maps of each view (Fig. 2).

Luminance map analysis showed that particularly southwest perimeter zone had the most critical luminance distribution within the visual field, which ranged from $13 \mathrm{~cd} / \mathrm{m}^{2}$ to $2050 \mathrm{~cd} / \mathrm{m}^{2}$. Three viewpoints (SW3, SW10, SW12) with the least uniform luminance pattern were identified, which were unsurprisingly located near the south-west facing window (Fig. 2). In the case of SW3, i.e, the luminance ratio between the VDU task and the side wall adja-

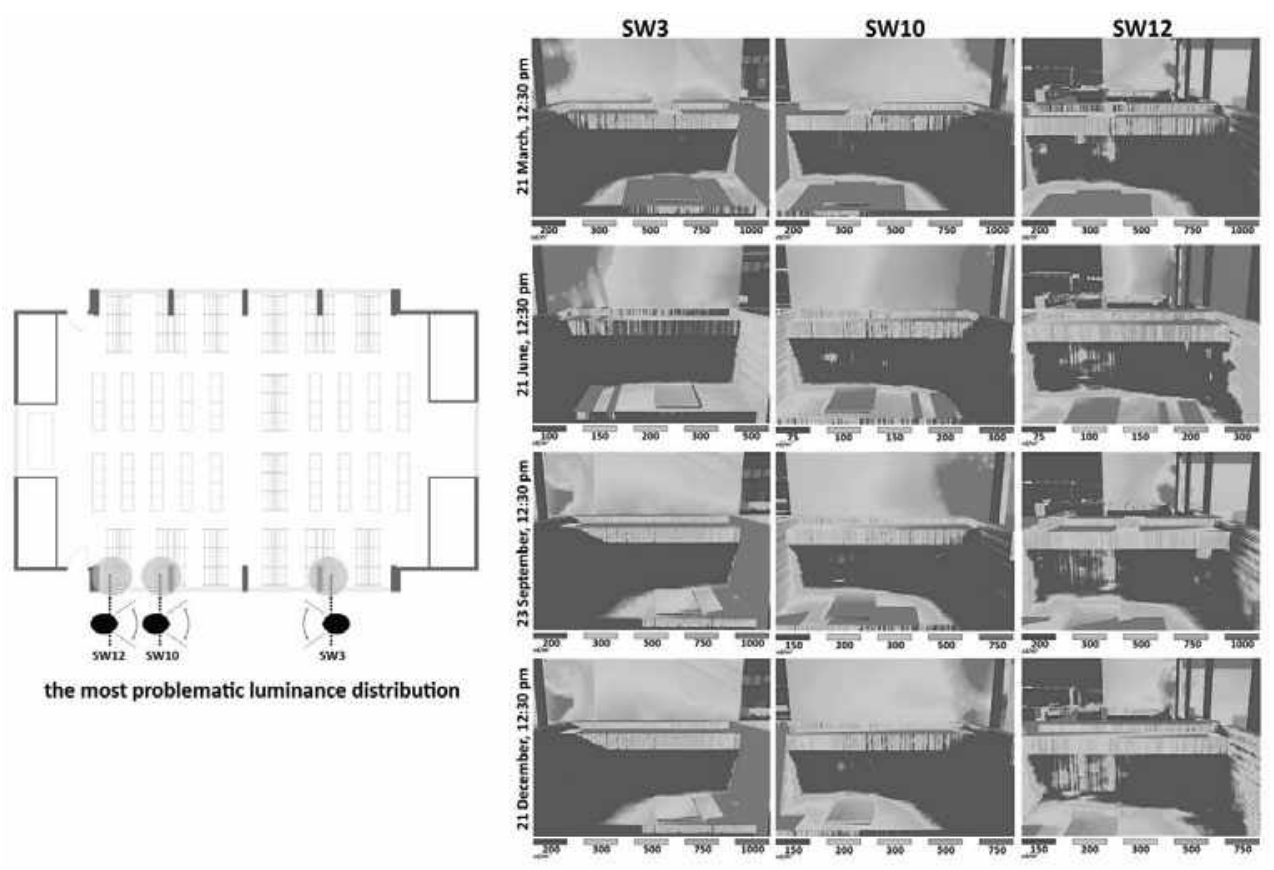

Fig. 2. Viewpoints with the poorest luminance distribution and luminance maps 


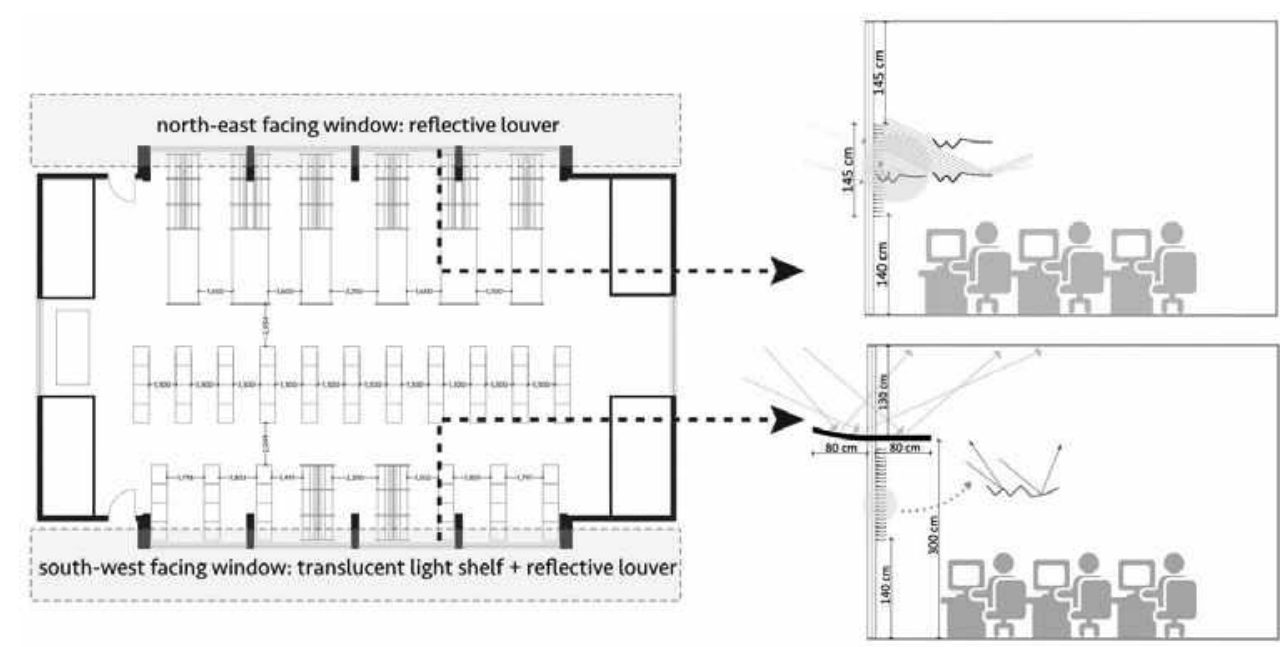

Fig. 3. Daylighting strategy on the plan layout and the cross sectional views showing its shape and principle cent to the window was found 1:43 on December 21 at $12: 30 \mathrm{pm}$, which is excessively high comparing to the recommended 1:10 ratio. In all cases, the luminance ratio between the paper task and VDU task ranged from $1: 12$ to $1: 158$, which again violates the recommendations and leads to an unsatisfactory perception for the library users.

\subsubsection{Illuminance on Workplane and Uniformity}

Illuminance in all cases shows an uneven distribution with a wide range of variation from very low levels to thousands. Peaks of illuminance occur at points (SW1-SW12), which were placed next to the south-west facing glazings. Rapid decreases are observed with the distance from the windows in the same zone (SW25-SW36). Illuminance distribution of north-east oriented points (NE1-NE36) appears relatively more uniform ranging from $46 \mathrm{~lx}$ to $1180 \mathrm{~lx}$, while it shows the lowest values, i.e. between $95 \mathrm{~lx}$ and $396 \mathrm{~lx}$, at the centre zone. To conclude, uniformity on the workplane throughout the room inherently appears poor, which is considerably lower than the standards (recommended illuminance for paper-based tasks in libraries in IES standards is between $500-1000 \mathrm{~lx}$; useful daylight illuminance in workspaces is between 100-2000 lx) (Table 3).

\subsection{Daylighting Strategy Proposal}

New daylighting strategies were proposed for south-west facing (a light shelf made of translucent material with a reflective coating shelf and reflective louvers) and north-east facing windows (reflective louvers) to improve illuminance and luminance distributions (Fig. 3). The systems are chosen based on the conclusions drawn from the literature and actual products [12-14]. A light shelf was positioned to the south-west facade throughout the glazing at $3.00 \mathrm{~m}$ from the floor with a depth of $1.6 \mathrm{~m}$. The light shelf modelled as external and internal was defined as specular with a reflectance value of $85 \%$. The internal reflective louver chosen from Retrolux Archive [14] components with a reflectance value of $85 \%$ for the south-west facing window were placed between $1.40 \mathrm{~m}$ and $2.85 \mathrm{~m}$ above the ground. It provides shading additionally. Each lamella has $13 \mathrm{~mm}$ depth, and the spacing between two lamellas is $0.5 \mathrm{~cm}$. The identical reflective louver system was applied to the north-east facing window as well.

\section{RESULTS}

\subsection{Luminance Based Findings}

The luminance ratios within the field of view have substantially found the balance regarding visual performance standards. The shading-redirecting function of the system played a strong role in that sense. Viewpoints SW3 and SW10 were the worst ones due to the very bright side wall surfaces just in front of the viewers, which are fully covered by sun patches. Improving the impact of the redirecting system on luminance distribution on the wall surface is much stronger and clearer in SW3 and SW10 than SW12. Nevertheless, the shading-redirecting effect of the system can be seen well in all three viewpoints perceiving the surfaces within the field of views with a more balanced luminance distribu- 
Table 3. Illuminance on Workplane and Uniformity Ratios ( $E$ : illuminance, avg: average, min: minimum, max: maximum, $U$ : uniformity).

\begin{tabular}{|c|c|c|c|c|c|}
\hline $\mathbf{1 2 : 3 0 ~ p m}$ & $\boldsymbol{E}_{\text {avg }}(\mathbf{l x})$ & $\boldsymbol{E}_{\boldsymbol{m i n}}(\mathbf{l x})$ & $\boldsymbol{E}_{\boldsymbol{m a x}}(\mathbf{l x})$ & $\boldsymbol{U}_{\mathbf{1}}\left(\boldsymbol{E}_{\boldsymbol{m i n}} / \boldsymbol{E}_{\boldsymbol{m a x}}\right)$ & $\boldsymbol{U}_{\mathbf{2}}\left(\boldsymbol{E}_{\boldsymbol{m i n}} / \boldsymbol{E}_{\text {avg }}\right)$ \\
\hline March 21 & 1358 & 114 & 6610 & 0.017 & 0.083 \\
\hline June 21 & 430 & 48 & 1060 & 0.045 & 0.111 \\
\hline September 23 & 1686 & 97 & 7970 & 0.012 & 0.057 \\
\hline December 21 & 910 & 46 & 4700 & 0.009 & 0.050 \\
\hline
\end{tabular}

tion. The excessive daylight on desk surfaces is balanced in all viewpoints providing a clear visual perception on the writing/reading task area.

The system functions as desired, i.e. on September 23 for SW10 and SW12, but less for SW3 that slightly observes sun patch traces on the wall surface particularly in the winter solstice. The most dramatic reductions in luminance ratios defined on screen, on paper, and on partitions were observed during the equinoxes. Luminance ratio between the paper task and desk partition on 21 March changed from 13.5:1 to 1.9:1 (SW12), 14:1 to 2.9:1 (SW10), 13:1 to $1: 1.6$ (SW3), which are providing recommended ratio $(\leq 5: 1)$ based on the standards. Lumi- nous variability is slightly higher in SW3 than in the others, but still within the recommended values; i.e. desk-to-side wall luminance ratios are 1:3 in SW12, 1:3 in SW10, and 1:3.8 in SW3 in spring equinox. Or, paper-to-desk ratios in spring equinox are found to be reasonably good indicators of the performance of shading-redirecting system as respectively 1.6:1 in SW12, 1.6:1 in SW10, and 1.8:1 in SW3.

Luminance values were substantially fixed with respect to the recommended ratios, except the ratios between screen and paper luminance when compared to the actual case. Paper-to-screen ratio is identified as between 1:2.5 to 1:3 in standards; however, results are higher, i.e. spring equinox indicated
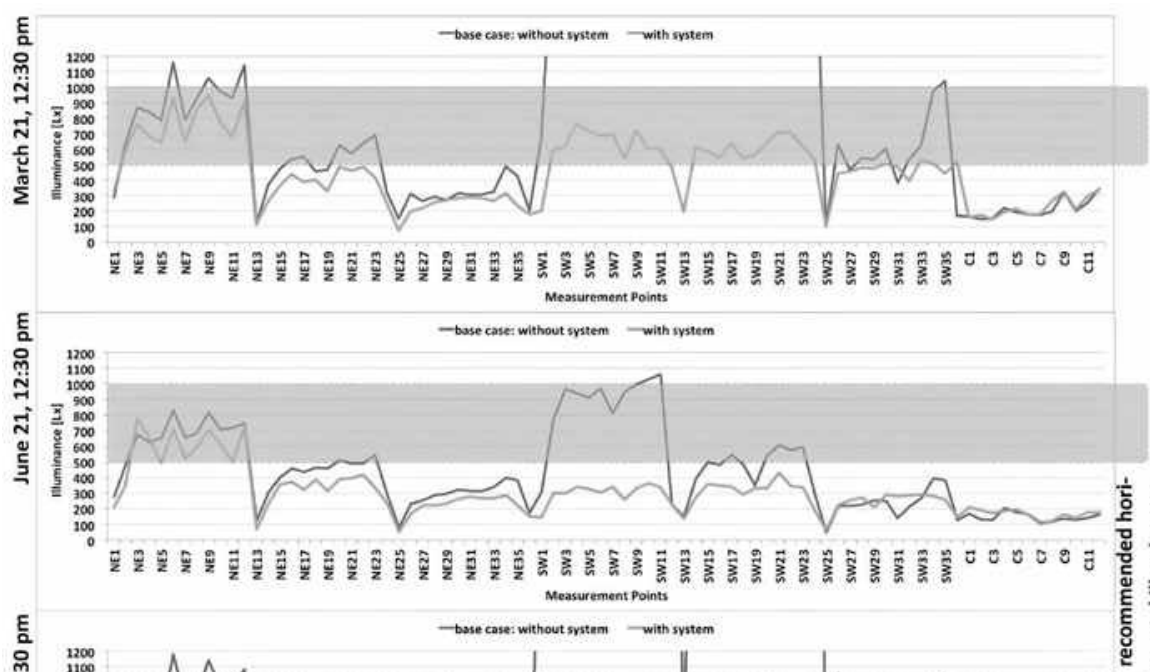

Fig. 4. The illuminance based effect of daylighting strategy on measurement points 


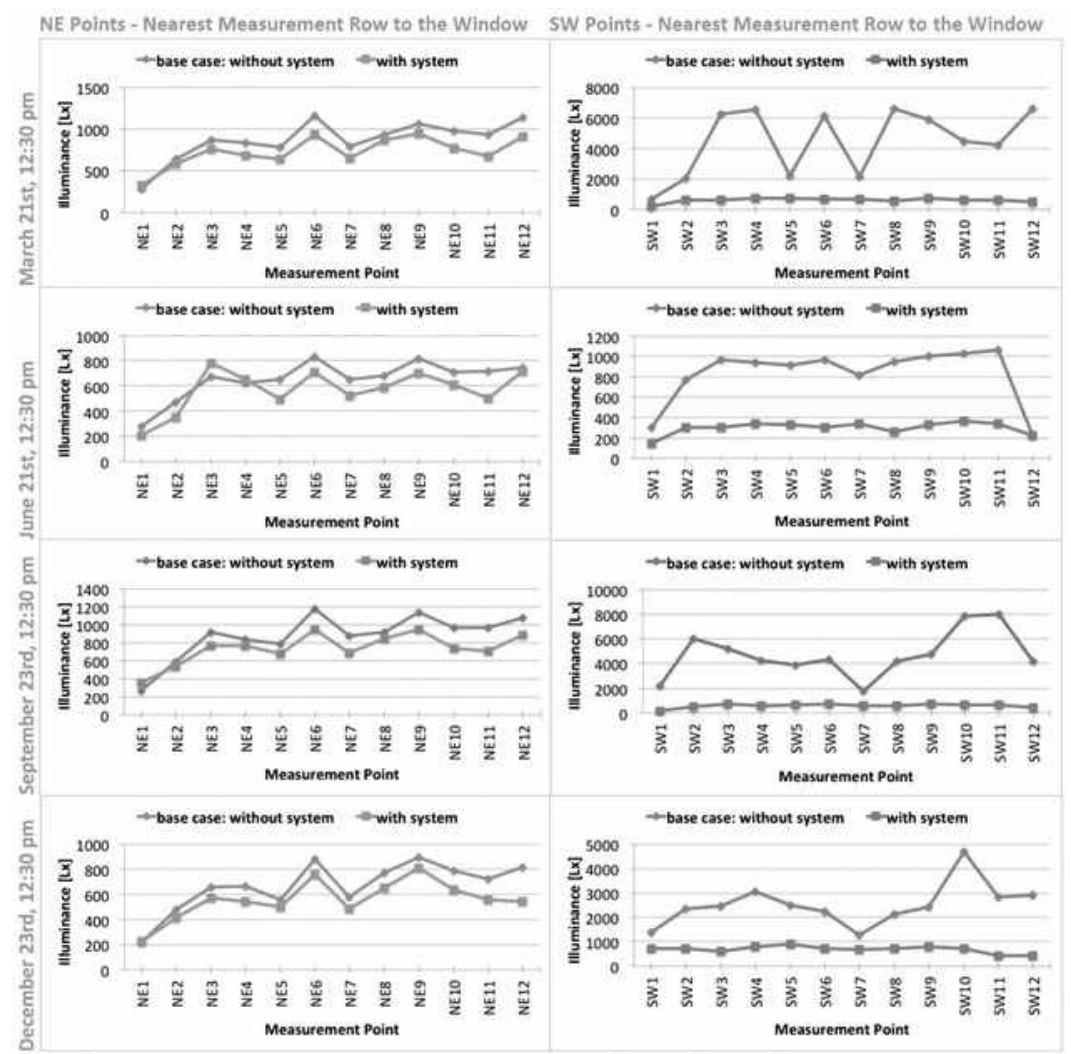

Fig. 5. Illuminance variation of the points near the windows (NE1-NE12 and SW1-SW12) that the average paper-to-screen ratio decreased from $1: 174$ to $1: 15$ for SW12, from $1: 191$ to $1: 35$ for SW10, from 1:216 to 1:42 for SW3, which are considerably high.

\subsection{Illuminance and Uniformity Based Findings}

Illuminance on almost every point experience diminution in all cases, resulting in a decrease in the average horizontal illuminance (Fig. 4). These findings may be considered adversely since the percentage of points between recommended values falls; i.e. from 1358 1x to 454 lx (-66 \%) on March 21, from $4301 \mathrm{x}$ to $302 \mathrm{~lx}$ (-29\%) on June 21, from $16861 x$ to 431 lx (-74\%) on September 23, from $9101 x$ to $378(-58 \%)$ lx on December 21, respectively. Yet, considering the recommendations of useful daylight illuminance values (100-2000) 1x, the average horizontal illuminance of March 21, September 23, and December 21 have come close to the recommended range after the retrofitting applications. Almost $80 \%$ of the calculated region below the IES standards satisfies the useful daylight illuminance range with a reasonable daylight availability. The potential reason, why only a few points are within the recommended range in June, can be explained with the high solar altitude during the summer solstice, which was already insufficient before the daylighting strategy. Illuminance falls the most dramatically at near window locations, but not at the centre zone. The system actually works as planned by mostly diminishing the excessive amounts of illumination near windows and not much affecting the points that are far from the windows.

Illuminance based improvement of 24 measurement points near the window (NE1-NE12 and SW1-SW12) are shown in Fig. 5 emphasizing the shading efficiency of the daylighting strategy. The most striking change appears in terms of illuminance variation, particularly on southwest points. The system balanced the illuminance distribution among the aforementioned measurement points as it was expected, i.e. the trendlines on March 21, June 21, September 23, and December 21 appear to be almost linear throughout the majority of southwest points, but not much in the sense of northeast points. Illuminance range of northeast points was already between $220-1160 \mathrm{~lx}$, which is an acceptable range according to the standards. In this case, the main consideration while applying the reflective louver system was to deliver daylight to the deeper parts of the space instead of blocking 


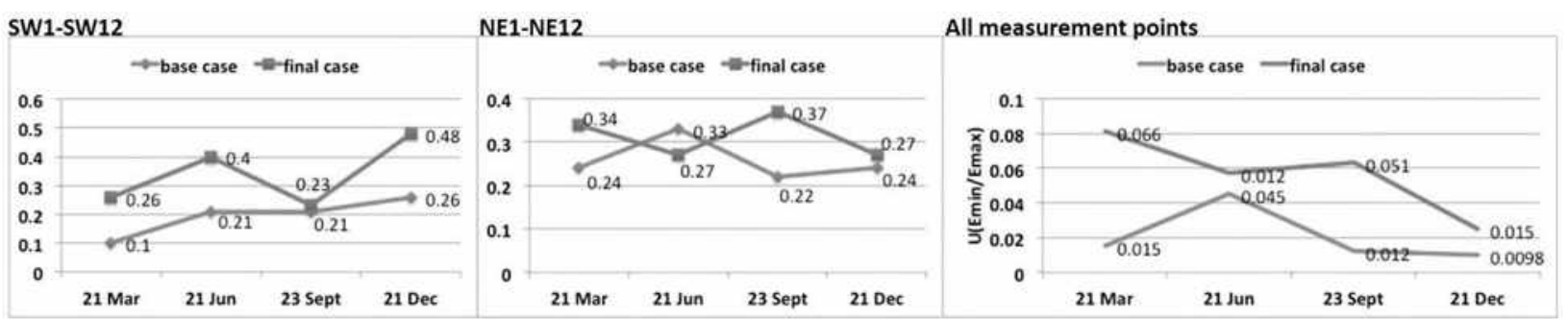

Fig. 6. Uniformity ratios before and after the daylight strategy (base and final case)

the sunlight. The system was successful to satisfy higher uniformity in every season in the third measurement row (NE25-NE36), specifically in December showing the strong redirecting effect of the system. The majority of northeast points remained very close to the base case illuminance, neither showing noticeable decrease nor increase, as desired at the beginning.

Fig. 6 illustrates the uniformity ratios $\left(E_{\min } / E_{\max }\right)$ across the whole space in solstices and equinoxes. Even the worst uniformity ratio of the base case performed an improvement of $53 \%$, which belongs to the winter solstice, while the rest of the experiment days showed an improvement between $166 \%$ and $340 \%$. Still being below the current uniformity standards, these ratios are found to be acceptable considering the large floor area of the case and the high number of measurement points. Specifically, better uniformity ratios are attained, except in NE in June.

\section{CONCLUSION}

The application of a translucent light shelf and reflective louvers improved the uniformity of both illuminance and luminance distribution by minimizing the incoming daylight near the window and maintaining or slightly maximizing it at the deep.

The most striking improvement observed after the daylight system application was the luminance distribution, since it blocks the excessive daylight filtering inside the space and redirects it to the deeper parts of the library. Specifically, the system with its shading-redirecting impact performed the best during equinoxes improving the unbalanced luminance distribution on surfaces within the visual field, i.e., the ratio of paper-to-desk partition was found to be significantly improved (79-85\%) and provided the recommended ratios.

The system notably maintained the target illuminance specifically on the most problematic measurement points, which are the nearest row to the window. Reaching up to $80 \%$ of improvement rate when compared to the base case, $75 \%$ of these points satisfied the IES standards that are required for meeting visual tasks, while $100 \%$ of them were calculated within the UDI range. Uniformity ratios were positively and significantly correlated with the more balanced illuminance distribution across space. Though still can not meet the required uniformity ratios of IES standards, an improvement of (53-340) \% was observed when compared to the base case. To satisfy the target uniformity ratio in such spaces with a fairly large floor area is a challenging and almost impossible task to accomplish. The improvement of the uniformity ratio here may remain to be a successful step.

In overall, the big picture gives the clues on how a proper design of a daylighting system provides a noticeable improvement in visual performance of a library having these building specifications; yet, one should keep in mind that in some cases even the proposed design solutions are not able to guarantee the ratios suggested in literature.

\section{REFERENCES}

1. Pniewska A., Brotas L. Daylight and productivity in a school library // Proceedings of CISBAT 2013, 2013, Lausanne, Switzerland, Vol. 1, pp. 341-346.

2. Reinhart C., Selkowitz S. Daylighting - Light, form, and people // Energy and Buildings, 2006, Vol. 38, \#7, pp. 715-717.

3. Konis K. Evaluating daylighting effectiveness and occupant visual comfort in a side-lit open-plan of office building in San Francisco // Building and Environment, California, 2013, Vol. 59, pp. 662-677.

4. Keskin Z., Chen Y., and Fotios S. Daylight and seating preference in open-plan library spaces // The International Journal of Sustainable Lighting, 2015, \#1, pp. 12-20.

5. Dogan T., Stec P. Prototyping a facade-mounted, dynamic, dual-axis daylight redirection system // Lighting Research and Technology, 2016, pp. 1-13. 
6. Baker N., Steemers K., Compagnon R., and Parpairi K. Daylight Design of Buildings // London: James \& James Science Publisher, London, 2002.

7. Solar Heating and Cooling Programme (SHCP), Daylighting in buildings: design tools and performance analysis, 1999. URL: http://www.ieo-shc.org/task 21/ publications/

8. Kazanasmaz T., Firat Örs P. Comparison of advanced daylighting systems to improve illuminance and uniformity through simulation modelling // Light and Engineering, 2014, Vol. 22, \#3, pp.56-66.

9. Kontadakis A., Tsangrassoulis A., Doulos L., and Topalis F. An active sunlight redirection system for daylight enhancement beyond the perimeter zone // Building and Environment, 2017, Vol. 113, pp. 267-279.

10. Jakubiec J.A. Building a database of opaque materials for lighting simulation // Proceedings of PLEA 2016 Los Angeles - 36th International Conference on Passive and Low Energy Architecture, 2016, Los Angeles, California, USA.

11. Bayram G., Kazanasmaz T. Simulation based retrofitting of an educational building in terms of optimum shading device and energy efficient lighting criteria // Light and Engineering, 2016, Vol. 24, \#2, pp. 45-55.

12. Moazzeni M.H., Ghiabaklou Z. Investigating the influence of light shelf geometry parameters on daylight performance and visual comfort, a case study of educational space in Tehran, Iran // Buildings, 2016, Vol. 6, \#4, pp. 1-16.

13. Freewan A.A. Maximizing the lightshelf performance by interaction between lightshelf geometries and a curved ceiling // Energy Conversion and Management, 2010, Vol. 51, \#8, pp. 1600-1604.

14. Retrosolar. Information about Retrolux. URL: http://www.retrosolar.de/flash/ani_rlx_e.html [Accessed 11 June 2017].

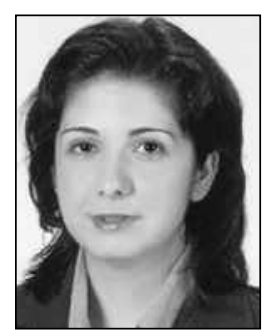

\section{Tuğçe Kazanasmaz,}

Ph.D. in Building Science from Middle East Technical University (METU). She has 18 years academic experience in architectural lighting, building physics, and energy efficient design. At present, she is a Professor in the Department of Architecture in İzmir Institute of Technology, Turkey

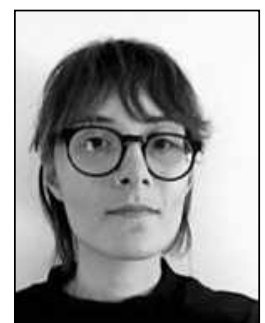

\section{Merve Öner,}

M. Sc. in Architecture from Izmir Institute of Technology in 2017. She holds her undergraduate degree obtained from Yaşar University as B. Sc. (Eng) in Architecture in 2012. Her research topics are architectural lighting and computer based simulations. She is still a Ph.D. candidate in the Department of Energy Engineering, Systems, Territory, and Construction in University of Pisa, Italy since 2017 